\title{
Organizational Culture and Its Association with Job Satisfaction among Hospital Employees
}

\author{
Divya Saxena $^{1}$, Ruchi Kanhere ${ }^{2}$, John Varghese Thekkekara ${ }^{3}$ \\ ${ }^{1}$ Project Officer, ${ }^{2}$ Assistant Professor, ${ }^{3}$ Professor, \\ ${ }^{1}$ St. John's Research Institute, \\ ${ }^{2,3}$ Department of Hospital Administration, St Johns Medical College, Bangalore, India \\ Corresponding Author: Ruchi Kanhere
}

DOI: https://doi.org/10.52403/ijhsr.20220239

\begin{abstract}
Introduction: Organizations are dynamic places; health care organizations are service organizations with a complex social system of employees. Organizational culture is commonly defined as the shared values, beliefs, and assumptions that guide employees' behavior and work style, thus affecting performance and job satisfaction. This study examines organisational culture and determines the association between organizational culture and job satisfaction.

Methodology: It was a descriptive cross-sectional survey study where the study population was categorized into clinical and non-clinical categories. A total of 196 employees from 18 to 60years of age were included using stratified random sampling. Organizational Culture is measured using factors: Innovation and risk-taking, Openness, Identity, Result Orientation and Management Support. Job satisfaction is measured using variables: Job nature, Job security, Talent used in the job, working hours, relationship with co-workers and supervisors, and Job recognition. Participants' responses were recorded on the Likert scale. ANOVA, T-test, and chi-square test were used to analyze the data Results: The study finds that "Identity" and Openness" are dominant cultural factors. $90.5 \%$ of the employees who said Organisation culture is good rated their satisfaction level as good.100\% of the clinical staff said they take pride in working for the organisation and study and culture and Job satisfaction association $\mathrm{P}$-value is $<0.001$

Conclusion: The study setting finds a strong association between Organizational Culture and job satisfaction and finds majority of the employees are highly satisfied
\end{abstract}

Keywords: Organization Culture, Job Satisfaction, and Job Satisfaction Association

\section{INTRODUCTION}

Organizations are dynamic places with a complex social system of employees where organizations and employees both influence each other in terms of social and work norms. Healthcare organizations are service organizations where the interactions with people within the organization and the engagement with the beneficiaries of the service of the organizations are valuable and essential to the organization's very existence where turnover and absenteeism negatively affect the productivity, patient experience and serving capability. Organizational culture as a concept first emerged in the late 1970s and 1980s and soon became a critical management phenomenon. Organizational culture is commonly defined as the shared values, beliefs, and assumptions that guide and coordinate the behavior of employees within an organization. Many researchers have defined organizations culture. Schneider (1983) says how an organization conducts business is guided by its value systems and assumptions. ${ }^{1}$ in similar approach Robbins and Sanghi (2007) ${ }^{2}$ defines that Organizational culture is a set of values which the employees share, and it 
defines and guides the way people work together; this system of shared meaning distinguishes one organization from another and could have a remarkable effect on employees' commitment and performance, thereby job satisfaction. Every organization develops and maintains its own unique culture, which serves as a guideline for dealing with people.

Locke (1976, p.1300) defines job satisfaction as a positive emotional state resulting from one job experience. On the other hand, Schneider and Snyder (1975, p.318) defined job satisfaction as a personal evaluation of a job ${ }^{1}$ We can say job satisfaction is emotions felt by employees based on their evaluation of the job, and it is a critical factor that determines the productivity of the employees, of the organization and retention of the employees

Batlis (1980) $)^{3}$ was one of the first few studies attempted to determine the relationship between organizational culture and job satisfaction, and findings emerged that organizational clarity is a significant predictor of job satisfaction. SCHNEIDER and REICHERS (1983) ${ }^{4}$ found that organizational structure and individual interaction makes organizations climate. It influences the job attitude and performance of the employees, and thus it affects employee's perception of the job and the organization. Kerr and Slocum $(1987)^{5}$ find that the reward system in the organization makes an essential part of the culture, and it defines the relationship between the organization and employees They also find that employees develop unity, pride in membership, and loyalty to the organization in a hierarchically based reward system.

In contrast, a performance-based system weakens the sense of membership. Sheridan (1992) ${ }^{6}$ finds that variation in organizational culture values significantly impacts employees' job performance and employee retention. Sempane et al. (2002) ${ }^{7}$ finds a positive relationship between job satisfaction and Organizational culture and states that employees perceive some aspects of culture more positively than others, and gender impacts the culture's perception. Greenberg J, Baron RA (2003) ${ }^{8}$ states that culture plays several essential roles in an organization. Firstly, it generates a commitment to an organization's mission; Secondly, culture provides a sense of identity; thirdly, culture clarifies and reinforces standards of behavior by guiding employees' words and deeds. Lok and Crawford (2004) ${ }^{9}$ explore the effects of organizational culture and leadership styles on job satisfaction and find that innovative and supportive cultures and a consideration leadership style positively affect job satisfaction and commitment. Buitendach and de Witte $(2005)^{10}$ finds that for the organization's productivity, it is good that employees are happy with the job, which results in employee commitment Kaliski $(2007)^{11}$ says that job satisfaction is the primary thing that shows the path towards recognition, salary, promotion, and achieving the goals that fulfil their desires. In a study for a hospital, E Jacobs and Roodt (2008) $)^{12}$ finds that organizational culture interacts with job satisfaction practice of knowledge sharing among employees. Thus, it affects the turnover intention of the employees. Speroff et al. (2010) ${ }^{13}$ explores if organizational group culture shows better alignment with patient safety climate and finds that harmonious team culture than bureaucratic organizational culture in the organization culture is better aligned for quality improvement and patient safety. Ahmad and Veerapandian (2012) ${ }^{14}$ states that organizational culture leads to employee outcome; hence it is essential to see aspects of culture and ensure that individuals and their work environments are compatible. Tawfik El-Nahas et al. (2013) ${ }^{15}$ finds a strong positive relationship between job commitment and job satisfaction; an enhanced work environment strengthen employee commitments reduces turnover intention and absenteeism. Curry et al. (2017) ${ }^{16}$ finds that learning environment and senior management support supports the high performance of the employees and 
better clinical outcomes in the hospitals. Dirisu et al. (2018) 17 finds that organizational culture has a significant and positive impact on job satisfaction and performance, and businesses should leverage their culture and instil values to improve performance. Healthcare organizations, like other organizations, must cultivate a culture of active participation and personal responsibility in which employees feel a sense of affinity with the organization. Strong organizational culture enables and nurtures the new behaviors, actions, and investments required to navigate the healthcare industry's numerous changes, especially the shift to value-based care

\section{AIMS AND OBJECTIVES}

Our literature survey showed that minimal studies have looked into the organizational culture in hospitals at large, particularly in the Indian private healthcare context, where private healthcare organizations hold a significant share of the total quantum of healthcare organizations in the country. In addition, we identified a void in the published literature in exploring the relationship of organizational culture with job satisfaction. As a result, this study attempted to bridge the gap with the following objectives: (a) To examine the existing organizational culture and identify if it is homogenous (b) To determine the association between organizational culture and job satisfaction.

\section{RESEARCH METHODOLOGY}

It was a descriptive cross-sectional survey study where the study population was categorized into clinical and nonclinical categories based on their involvement with direct patient care. Under Clinical Category, nurses, nursing in charge, Lab technicians, and physiotherapists were selected. Under Non-Clinical Category Administration staff: clerks, helpers, ward aids, Pharmacist, billing, and Secretarial staff was selected. A total of 200 employees enrolled for the study, with 20 participants enrolled from each subcategory using the fixed quota sampling method to ensure equal participation. The individual subjects were selected using a stratified random sampling technique. The response rate was 98 percent, resulting in the final sample size of 196, where 96 respondents were from Clinical, and 100 respondents were from the non-clinical category of the employees

A structured questionnaire with details on demographics and two sections, (A) organizational culture (B) job satisfaction, was used as the tool. Subject experts validated the tool, which was developed based on the theory of Organization culture and previously published studies on Job satisfaction. Theory of organization culture given by Stephen Robbins $(2007)^{2}$ is used as a framework to examine organizational culture factors. The following factors were considered for the study, Innovation and risk-taking (factor1), Openness (factor 2), Identity (factor 3), Result Orientation (factor 4), and Management support (factor 5). The job satisfaction questions which formed the B part of the tool were adopted based on the study done by (Habib et al., 2014) ${ }^{18,}$ which is available at an open domain; hence author permission has not been sought. The questions were based on the following variables: Job nature, Job security, Talent used in the job, working hours, relationship with co-workers and supervisors, and Job recognition

All questions were rated using a five-point scale where the following scores were used: "Strongly agree" $=5$, "agree" $=4$, "Neutral" =3, "disagree" =2 and "strongly disagree" $=1$

Collected data analyzed using $\mathrm{R}$ version 4.1.0( $\mathrm{R}$ core team. 2021 Viana Austria) version. Organizational factors were scored and ranked using Mean values. Association of Organizational factors with different age groups is analyzed using oneway ANOVA and gender, marital status using independent T-test. Chi-square test is done to check the association of 
Organizational culture level and Job satisfaction level of the employees

HYPOTHESES: H1: The homogenous and strong organisational culture of an organisation has a positive relationship with the Job satisfaction of the employees

\section{ANALYSIS}

\section{Demographic analysis:}

The total study population was 196 , where the study had a significantly higher number of female participants than male participants. Most of the participants were relatively freshers having up to 5 years of work experience and almost equal representation from employees from different age groups

Table 1 Demographics of the study population

\begin{tabular}{|l|l|l|}
\hline Demographic details N= 196 & Percentage \\
\hline Variable & Frequency & $19 \%$ \\
\hline Gender & 38 & $81 \%$ \\
\hline Male & 158 & $66 \%$ \\
\hline Female & 130 & $34 \%$ \\
\hline Marital Status & 66 & $43 \%$ \\
\hline Married & $22 \%$ \\
\hline Unmarried & 85 & $15 \%$ \\
\hline Experience & 44 & $19 \%$ \\
\hline 0-5years & 30 & $29 \%$ \\
\hline 6-10years & 37 & $38 \%$ \\
\hline 11-15years & \multicolumn{2}{|l|}{} \\
\hline 16-20\&above & 56 & $23 \%$ \\
\hline Age & 74 & $11 \%$ \\
\hline 18-25yrs & 45 & \\
\hline 26-35 & 22 & \\
\hline 36-46 &
\end{tabular}

\section{Organization culture factors}

The data analysis of the organizational culture finds that the factor "Identity" is the dominating factor in the organization that shows employees feel that employees of the institute "take pride working in the institute."

"People know the goals of the department" and "people work well together."; "employees are encouraged to make decisions", "the communication channel between management" and "coordination between departments is good".100\% $(\mathrm{n}=96)$ staff says they take pride in working for the institute

Ranking of the factors as scored by the employees is: Rank 1 :(Factor- Identity) Mean 76.62 \pm 17.77 , Rank 2:(Factor Openness) Mean 71.22 \pm 19.49 , Rank 3:(Factor - Innovation and risk-taking) Mean 62.37 \pm 22.54 , Rank:4 (Factor Organizational Support) Mean 61.14 15.94, Rank 5: (Factor -Result Orientation) $6260.97 \pm 21.9$

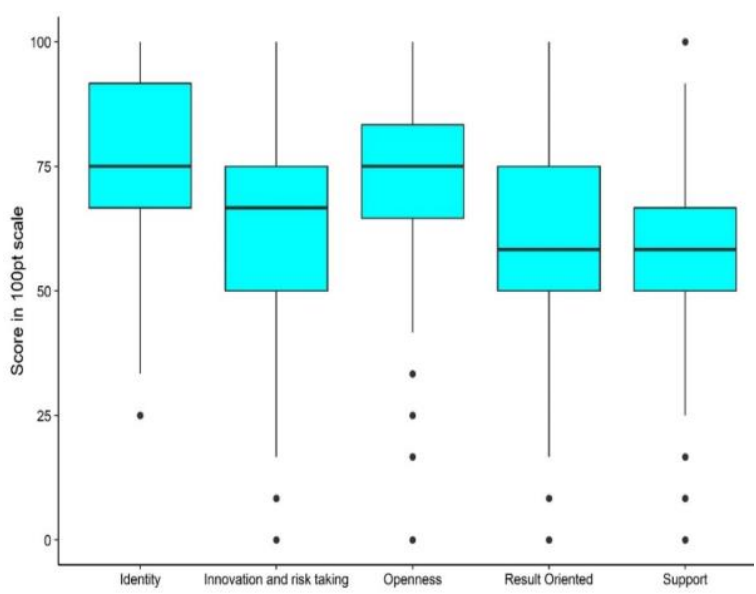

Chart -1 Box plot shows the Organizational culture Factors distribution across Organization

All these factors were analyzed with relation to Gender and different age groups category of employees to see how factor varies on those parameters

When factors were analyzed for gender, it was found that for factors "support" and "Result orientation", gender differences tend to be significant. In addition, differences tend to be significant when factors were analyzed for different age groups for "support" and "Result orientation". Finally, when data analyzed for clinical and non-clinical category differences, they tend to be significant for factor "support."

Table 2 Organizational Culture factors and Demographic Variables

\begin{tabular}{|c|c|c|c|c|c|}
\hline \multicolumn{6}{|c|}{ Organizational Culture Factors and Demographic Variables } \\
\hline Variables & Innovation and Risk Taking & Openness & Identity & Support & Result Orientation \\
\hline \multicolumn{6}{|l|}{ Gender } \\
\hline Male & $59.86 \pm 20.02$ & $67.76 \pm 20.05$ & $72.58 \pm 21.12$ & $56.79 \pm 10.58$ & $55.48 \pm 20.89$ \\
\hline female & $62.97 \pm 23.12$ & $72.04 \pm 19.32$ & $77.58 \pm 16.79$ & $62.18 \pm 16.84$ & $62.28 \pm 21.99$ \\
\hline$P$ value & 0.409 & 0.239 & 0.181 & 0.015 & 0.08 \\
\hline
\end{tabular}




\begin{tabular}{|c|c|c|c|c|c|}
\hline \multicolumn{6}{|c|}{ Table 2 Continued... } \\
\hline \multicolumn{6}{|l|}{ Age group } \\
\hline $18-25 \mathrm{Y}$ & $58.77 \pm 23.53$ & $70.08 \pm 18.92$ & $76.48 \pm 17.48$ & $63.54 \pm 17.37$ & $66.07 \pm 18.99$ \\
\hline $26-35 Y$ & $63.73 \pm 22.13$ & $0.27 \pm 20.60$ & $76.23 \pm 18.69$ & $60.81 \pm 14.64$ & $59.12 \pm 22.33$ \\
\hline $36-46 \mathrm{Y}$ & $66.09 \pm 25.75$ & $72.91 \pm 20.50$ & $75.75 \pm 19.08$ & $56.25 \pm 17.34$ & $61.74 \pm 23.52$ \\
\hline$>46 \mathrm{Y}$ & $59.46 \pm 11.29$ & $73.86 \pm 15.27$ & $79.92 \pm 12.50$ & $65.9 \pm 10.88$ & $52.65 \pm 22.03$ \\
\hline$P$ value & 0.355 & 0.779 & 0.827 & 0.059 & 0.078 \\
\hline \multicolumn{6}{|c|}{ Clinical and Non-clinical } \\
\hline Clinical & $62.23 \pm 24.18$ & $71.52 \pm 21.31$ & $75.95 \pm 18.33$ & $64.32 \pm 19.25$ & $62.93 \pm 19.34$ \\
\hline Non-clinical & $62.5 \pm 20.97$ & $70.91 \pm 17.66$ & $77.25 \pm 17.28$ & $58.08 \pm 11.20$ & $59.08 \pm 24.04$ \\
\hline$P$ value & 0.936 & 0.828 & 0.612 & 0.007 & 0.217 \\
\hline
\end{tabular}

\section{Job Satisfaction and Organizational Culture Assessment}

Job satisfaction assessment for the study population shows that $83 \%(n=163)$ of the employee said they are satisfied, only 16 $\%(\mathrm{n}=33)$ of the employees are moderately satisfied, and none of the employees falls in poor job satisfaction. Organizational work culture assessment shows that $43 \%(n=84)$ says that work culture is good, $55 \%(\mathrm{n}=109)$ says it is moderate, and only $1.5 \% \quad(n=3)$ says it is poor. Among both clinical and non-clinical groups of employees, factors such as "Clear job responsibilities at work", "Harmonious relationship with the supervisor and colleagues", "Taking pride in the institute's work", and "Appropriate use of skills" made most employees satisfied. Every single clinical employee is proud to be a part of the institute." Gender difference" and Category of employees is not significant for Job satisfaction

Table 3: Job Satisfaction and Organizational culture assessment

\begin{tabular}{|c|c|c|}
\hline \multicolumn{3}{|c|}{$\begin{array}{l}\text { Job satisfaction, Organizational culture, and Demographic } \\
\text { Variables }\end{array}$} \\
\hline Variables & Job satisfaction & Organizational culture \\
\hline \multicolumn{3}{|c|}{ Gender\& Age group } \\
\hline Male & $74.52 \pm 1510$ & $62.5 \pm 13.56$ \\
\hline Female & $73.2 \pm 2.92$ & $67.41 \pm 13.85$ \\
\hline $\mathrm{P}$ value & 0.501 & 0.051 \\
\hline $18-25 \mathrm{Y}$ & $75.36 \pm 11.05$ & $66.99 \pm 15.07$ \\
\hline $26-35 Y$ & $70.82 \pm 14.89$ & $66.03 \pm 14.88$ \\
\hline $36-46 Y$ & $73.96 \pm 9.26$ & $66.55 \pm 13.09$ \\
\hline$>46 \mathrm{Y}$ & $76.44 \pm 11.16$ & $66.36 \pm 8.75$ \\
\hline $\mathrm{P}$ value & 0.112 & 0.985 \\
\hline \multicolumn{3}{|c|}{ Clinical and Non-Clinical } \\
\hline Clinical & $73.39 \pm 14.49$ & $67.39 \pm 14.48$ \\
\hline Non-Clinical & $73.52 \pm 10.15$ & $65.56 \pm 13.32$ \\
\hline $\mathrm{P}$ value & 0.941 & 0.359 \\
\hline
\end{tabular}

Organizational culture, when assessed for the clinical and non-clinical category of the employee's obtained result, is non-significant, which implies that there is no difference of culture between the clinical and non-clinical group of employees and organizations have a homogenous culture

\section{FINDINGS}

$90.5 \%$ of the employees who said Organisation culture is good rated their satisfaction level as good; hence we found that culture in the existing Organisation is strong, and it has a significant association with job satisfaction

Table 4

\begin{tabular}{|c|c|c|c|}
\hline \multicolumn{4}{|c|}{ Association of OB culture Level and Job Satisfaction Level } \\
\hline \multirow[t]{2}{*}{ OB culture Level } & \multicolumn{2}{|c|}{ Job Satisfaction Level } & \multirow[b]{2}{*}{ P value ${ }^{x}$} \\
\hline & Moderate & Good & \\
\hline Poor & $3(100 \%)$ & $0(0 \%)$ & \\
\hline Moderate & $22(20.2 \%)$ & $87(79.8 \%)$ & $<0.001$ \\
\hline Good & $8(9.5 \%)$ & $76(90.5 \%)$ & \\
\hline
\end{tabular}

${ }^{\sharp}$ Chi square test

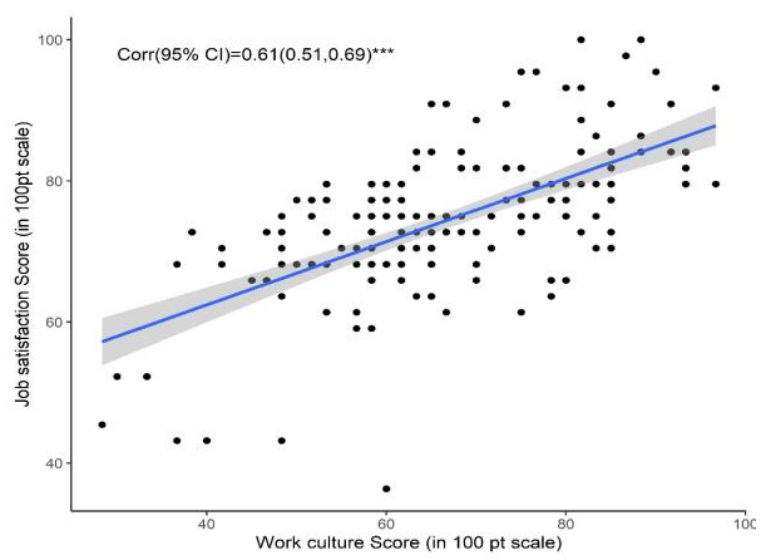

\section{DISCUSSION}

The research hypothesis was that the homogenous and strong organisational culture of an organisation has a positive relationship with the Job satisfaction of the employees The study indicates that the research setting has a homogenous and strong culture. Based on employees' responses, it is revealed that organizational culture is predominantly based on factors 
"Identity" and "Openness. Most of the employees showed high work satisfaction. According to (Sempane et al., 2002) ${ }^{7}$ study in a service organization, a significant relationship was found between organizational culture and job satisfaction and our study also found similar results Research from Jacobs and E Jacobs and Roodt (2008) $)^{12}$ finds that organizational culture interacts with Job satisfaction and decreases turnover intention among nurses. Our study does not explore turnover intention. However, we found that 100 per cent of clinical staff take pride in working for the institute, which shows a high level of satisfaction. Dimitrios et al. (2014) ${ }^{20}$ finds that organizational culture does not affect job satisfaction among administrative staff in a public hospital, and there is no correlation between satisfaction and culture. Our study had included non-clinical administrative staff, and our results were opposite to this study. Under organizational culture factors for "Support" and "Result orientation", the study finds gender difference tends to be significant. Cropley and Cropley (2017) ${ }^{19}$ find that a negative organizational climate suppresses female employees' innovation capacity.

In contrast, in our study setting, women have given the more favorable opinion that shows women employees feel well supported. However, employees are highly satisfied when we see job satisfaction irrespective of gender. In research from Chung and Ahn (2019) $)^{21}$ found that Innovation orientated culture showed a strong correlation with Job satisfaction, whereas, in our study, we found our study setting has more Organizational Identitybased culture

\section{CONCLUSIONS}

The study concludes that the study setting's organizational culture is strong, with factors "Identity" and "Openness" dominating factors. This study also finds homogenous culture where clinical and nonclinical categories exhibit the same organizational culture. This study also lends support to the theory that a homogeneous and robust organizational culture is linked to job satisfaction. The study setting finds a strong association between culture and job satisfaction. The study also finds slight gender differences in organizational factors where women employees feel the organization is supportive and people work well together

Acknowledgements: We acknowledge the support given for statistical analysis by $\mathrm{Dr}$ Santu Gosh, Professor Department of Biostatistics St Johns Medical College Bangalore

\section{Conflict of Interest: None}

\section{Source of Funding: None}

\section{REFERENCES}

1. Jaghargh FZ, Ghorbanpanah H, Nabavi SE, Saboordavoodian A, Farvardin Z. A survey on organizational culture based on Stephan Robbins's theory (Case Study). 2nd International Conference on Management and Artificial Intelligence IPEDR. 2012;35

2. Robbins, S. P. and Sanghi, S. (2007). Organizational Behavior, Pearson Education, New Delhi.

3. Batlis NC. The effect of organizational climate on job satisfaction, anxiety, and propensity to leave. J Psychol [Internet]. 1980;104(3-4):233-40. Available from: http://dx.doi.org/10.1080/00223980.1980.12 062970.

4. Schneider B, Reichers AE. On the etiology of climates. Pers Psychol [Internet]. 1983;36(1):19-39. Available from: http://dx.doi.org/10.1111/j.17446570.1983.tb00500.x.

5. Kerr J, Slocum JW Jr. Managing corporate culture through reward systems. Acad Manag Perspect [Internet]. 1987;1(2):99107. Available from: http://dx.doi.org/10.5465/ame.1987.427581 7.

6. Sheridan JE. Organizational culture and employee retention. Acad Manage J [Internet]. 1992;35(5):1036-56. Available from: http://dx.doi.org/10.5465/256539.

7. Sempane ME, Rieger HS, Roodt G. Job Satisfaction In Relation To Organisational 
Culture. SA J Ind Psychol [Internet]. 2002;28(2). Available from: http://dx.doi.org/10.4102/sajip.v28i2.49.

8. Greenberg J, Baron RA. Behavior in Organizations: Understanding and Managing the Human Side of Work. Upper Saddle River: Prentice-Hall; 2003.

9. Lok P, Crawford J. The effect of organisational culture and leadership style on job satisfaction and organisational commitment: A cross-national comparison. J Manag Dev [Internet]. 2004;23(4):321-38. Available from: http://dx.doi.org/10.1108/026217104105297 85.

10. Buitendach JH, De Witte H. Job insecurity, extrinsic and intrinsic job satisfaction and affective organisational commitment of maintenance workers in a parastatal. S Afr J Bus Manag [Internet]. 2005;36(2):27-38. Available

from: http://dx.doi.org/10.4102/sajbm.v36i2.625.

11. Kaliski BS. Encyclopedia of Business and Finance. Thompson Gale, Detroit; 2007.

12. Jacobs E, Roodt G. Organisational culture of hospitals to predict turnover intentions of professional nurses. Health SA Gesondheid [Internet]. 2008;13(1):63-78. Available from: http://dx.doi.org/10.4102/hsag.v13i1.258.

13. Speroff T, Nwosu S, Greevy R, Weinger MB, Talbot TR, Wall RJ, et al. Organisational culture: variation across hospitals and connection to patient safety climate. Qual Saf Health Care [Internet]. 2010;19(6):592-6. Available from: http:// dx. doi.org/10.1136/qshc.2009.039511 .

14. Ahmad KZ, Veerapandian K. The mediating effect of person-environment fit on the relationship between organisational culture and job satisfaction. Int $\mathbf{J}$ Psychol Stud [Internet]. 2012;4(1). Available from: http://dx.doi.org/10.5539/ijps.v4n1p91.

15. El-Nahas T, Mohamed E, Yehia A. The impact of leadership behaviour and organisational culture on job satisfaction and its relationship among organisational commitment and turnover intentions. A case study on an Egyptian company [Internet]. Jbrmr.com. [cited 2022 Feb 14]. Available from:

https://www.jbrmr.com/cdn/article_file/i15_c-121.pdf.
16. Curry LA, Brault MA, Linnander EL, McNatt Z, Brewster AL, Cherlin E, et al. Influencing organisational culture to improve hospital performance in care of patients with acute myocardial infarction: a mixed-methods intervention study. BMJ Qual Saf [Internet]. 2018;27(3):207-17. Available from: http://dx.doi.org/10.1136/bmjqs-2017006989.

17. Dirisu J, Worlu R, Osibanjo A, Salau O, Borishade T, Meninwa $\mathrm{S}$, et al. An integrated dataset on organisational culture, job satisfaction and performance in the hospitality industry. Data Brief [Internet]. 2018;19:317-21. Available from: http://dx.doi.org/10.1016/j.dib.2018.04.137

18. Habib S, Aslam S, Hussain A, Yasmeen S, Ibrahim M. The impact of organizational culture on job satisfaction, employees commitment and turn over intention. Advances in Economics and Business. 2014;2(6):215-22.

19. Cropley D, Cropley A. Innovation capacity, organisational culture and gender. Eur $\mathbf{J}$ Innov Manag [Internet]. 2017;20(3):493510. Available from: http://dx.doi.org/10.1108/ejim-12-20160120

20. Dimitrios B, Kastanioti C, Maria T, Dimitris $\mathrm{N}$. The influence of organizational culture on job satisfaction of administrative employees at a public hospital: The case of General Hospital of Larissa. J Health Manag [Internet]. 2014;16(2):217-31. Available from: http://dx.doi.org/10.1177/ 0972063414526108

21. Chung HJ, Ahn SH. Relationship between organizational culture and job satisfaction among Korean nurses: A meta-analysis. J Korean Acad Nurs Adm [Internet]. 2019;25(3):157. Available from: http://dx.doi.org/10.11111/jkana.2019.25.3. 157

How to cite this article: Saxena D, Kanhere R, John Varghese Thekkekara. Organizational culture and its association with job satisfaction among hospital employees. Int J Health Sci Res. 2022; 12(2): 280-286. DOI: https://doi.org/10. 52403/ijhsr.20220239 